\title{
TSH-secreting pituitary adenoma
}

INSERM

\section{Source}

INSERM. (1999). Orphanet: an online rare disease and orphan drug data base. TSHsecreting pituitary adenoma. ORPHA:91347

A rare, functioning, pituitary adenoma characterized by the presence of a pituitary mass associated with high levels of circulating, free, thyroid hormones in conjunction with normal to high levels of TSH and unresponsiveness of TSH levels to TRH stimulation and T3 suppression tests, typically manifesting with signs and symtoms of mild to moderate hyperthyroidism (e.g. goiter (most frequently observed), palpitation, excessive sweating, arrhythmia, weight loss, tremor) and/or tumor mass effect (such as headache, visual field defects, hypopituitarism). Occasionally, cosecretion of prolactin and/or growth hormone may cause galactorrhea and/or acromegaly. 